\title{
Towards host-to-host meeting scheduling negotiation
}

\author{
Rani Megasari $^{\mathrm{a}, \mathrm{b}, 1, *}$, Kuspriyanto ${ }^{\mathrm{a}, 2}$, Emir Mauludi Husni ${ }^{\mathrm{a}, 2}$, Dwi Hendratmo Widyantoro ${ }^{\mathrm{a}, 2}$ \\ ${ }^{a}$ STEI Bandung Institute of Technology, Jl.Ganeca 10, Bandung 40132, Indonesia \\ ${ }^{b}$ Computer Science Department Indonesia University of Education, Jl. Setiabudhi 229, Bandung 40154, Indonesia

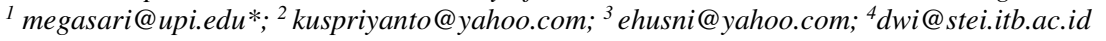

\begin{abstract}
ARTICLE INFO
ABSTRACT

Article history:

Received March 11, 2015

Revised March 26, 2015

Accepted March 31, 2015

Keywords:

Meeting Scheduling

Groupware Calendar System

Mechanism Design

Mutiagent Negotiation

Conflict Handling Mode

The Clarke Tax Mechanism

This paper presents a different scheme of meeting scheduling negotiation among a large number of personnel in a heterogeneous community. This scheme, named Host-to-Host Negotiation, attempts to produce a stable schedule under uncertain personnel preferences. By collecting information from hosts' inter organizational meeting, this study intends to guarantee personnel availability. As a consequence, personnel's and meeting's profile in this scheme are stored in a centralized manner. This study considers personnel preferences by adapting the Clarke Tax Mechanism, which is categorized as a non manipulated mechanism design. Finally, this paper introduces negotiation strategies based on the conflict handling mode. A host-to-host scheme can give notification if any conflict exist and lead to negotiation process with acceptable disclosed information. Nevertheless, a complete negotiation process will be more elaborated in the future works.
\end{abstract}

Copyright () 2015 International Journal of Advances in Intelligent Informatics.

\section{Introduction}

A real world problem of meeting scheduling comes from personnel involvement in a heterogeneous community. This problem triggers uncertain personnel availability time because of the emerging meeting request. A meeting schedule often needs to be rescheduled because of personnel's schedule collision. Due to the dynamic calendar density of personnel, a host meeting has no guarantee whether the personnel have 'free time' or not to be scheduled [1]. Conversely, disclosure of free time information of personnel leads to privacy issues [2].

In engineering domain, the research on meeting scheduling is conducted through the development of Groupware Calendar System [3]. Groupware Calendar System (GCS) is also called Computer Supported Cooperative Work (CSCW) for meeting scheduling. GCS uses a network for sharing electronic calendar. Its development takes three perspectives, which are individual user, socio-organizational environment, and technology. Moreover, GCS has been improved in several features, such as privacy management or event attendance prediction [4]. Unfortunately, disparity in work and benefit for personnel still result in the personnel's reluctance to use GCS or to give their preferences [3] [5]. As a consequence, incomplete information of personnel influences the effectiveness of scheduling result.

Meeting scheduling is about searching mutual time of personnel among their different activities, which is a challenging task. Reaching the agreement about the schedule becomes difficult since almost no time is truly free for all personnel. Therefore, meeting schedule must be booked in advance to announce about the meeting and personnel availability. However, the schedule that is already booked is not absolutely free of conflict. There is always a possibility of conflicts occurring after the schedule is made because there are other meetings that have a higher priority and takes the same timeslot. Meeting scheduling approach should consider the dynamic environment to successfully produce a meeting schedule or, at worst, if necessary re-scheduling can be done easier.

Multiagent negotiation is an approach which is already used to solve the meeting scheduling conflicts [5] [6] [7]. This approach uses agents as representation of personnel preferences. Each agent negotiates to reach an agreement among agents about the proper time to have a meeting. A host meeting decides the schedule based on the majority of mutual time among personnel. 
Nevertheless, this approach still has the probability to meet the risk of new conflicts caused by the dynamic of new meeting scheduling requests.

This paper explains about a different scheme of meeting scheduling negotiation. A meeting schedule satisfaction is influenced by personnel preferences, but personnel preferences can be fickle. This scheme uses agent representation which can control the dependence upon personnel preference to become a complementary scheme. This approach is called host-to-host meeting scheduling negotiation.

By using agent as host representation, this approach has two tasks. Firstly, as host, the agent must choose the proper timeslot that satisfies personnel preferences. This paper adapts the Clarke Tax Mechanism (CTM) to achieve the optimal social welfare and gain the personnel tax to be calculated in the negotiation process [8] [9]. Secondly, as host, the agent must arrange the meeting as well as possible, both in terms of the time selected and the personnel invited. Therefore, the agent negotiates the personnel availability with other agents or hosts who are in conflict, using negotiation strategy which is adapted from conflict handling mode [10]. The paper uses the term "personnel" instead of "participant" or "invitee" to emphasis the role variable as personnel profile. The personnel role influences negotiation consideration and will be studied in the future work.

\section{Related Work}

This study tells about negotiation approach to resolve a meeting scheduling conflict. This study is inspired of conflict management theory and multiagent negotiation whose complexity is influenced by calendar density.

\section{A. Calendar Density}

Calendar density is one of the variables used in meeting scheduling problem to measure the complexity of meeting scheduling nature[7]. In a heterogeneous community, every member of the personnel invited to a meeting has the probability to be connected to other meetings and scheduled by other hosts. Since a meeting scheduling task is about finding a mutual time of personnel's available time within a certain period, the less availability time of personnel will increase the complexity of meeting scheduling for a new meeting request, which is formulated below.

$$
\text { Calendar density }=\frac{\text { nslot }}{\text { navailableslot }}
$$

By considering personnel's calendar density, each host can choose a negotiation strategy when meeting a conflict. The alternative strategy can be personnel replacement or assigning an important role. Nevertheless, personnel's calendar density fluctuates. Therefore, the information about personal calendar in the global calendar is truly needed. Fig. 1 below shows calendar density of each member of the personnel through the centralization of personal calendar in the global calendar. The conflict takes place due to the unavailable timeslot within the periods of T1-T5 for all invited personnel.

$$
\begin{aligned}
& \text { Personal Calendar } 1 \text {, calendar density }=80 \% \quad \begin{array}{|l|l|l|l|l|}
\hline \mathrm{M}_{1} & & \mathrm{M}_{4} & \mathrm{M}_{5} & \mathrm{M}_{6} \\
\hline
\end{array} \\
& \text { Personal Calendar 2, calendar density }=40 \% \quad \begin{array}{l|l|l|l|l|}
\hline & \mathrm{M}_{2} & \mathrm{M}_{4} & & \\
\hline
\end{array} \\
& \text { Personal Calendar 3, calendar density }=60 \% \quad \begin{array}{ll|l|l|l|l|}
\cline { 2 - 5 } & \mathrm{M}_{1} & \mathrm{M}_{3} & & \mathrm{M}_{5} & \\
\hline
\end{array} \\
& \text { Personal Calendar } 4 \text {, calendar density }=60 \% \quad \begin{array}{ll|l|l|l|}
\hline & & \mathrm{M}_{4} & \mathrm{M}_{7} & \mathrm{M}_{6} \\
\hline
\end{array} \\
& \text { Personal Calendar 5, calendar density }=20 \% \\
& \begin{array}{lllll}
\mathrm{T}_{1} & \mathrm{~T}_{2} & \mathrm{~T}_{3} & \mathrm{~T}_{4} & \mathrm{~T}_{5}
\end{array} \\
& \text { the periode of a new meeting request }
\end{aligned}
$$



Fig. 1.Calendar density of each personnel 


\section{B. Conflict handling mode}

In conflict management theory, constraint satisfaction is represented by a pie. The decision to fulfill self-satisfaction is represented by a dark pie, while the decision inclined to satisfy other's satisfaction is represented by a light-colored pie as depicted in fig 1 . Since the nature of being selfish is assertiveness, this paper assumes similar condition in meeting scheduling nature, which is taking timeslot. Conversely, the nature of cooperativeness is assumed as the possibility to manipulate the constraint through negotiation process.

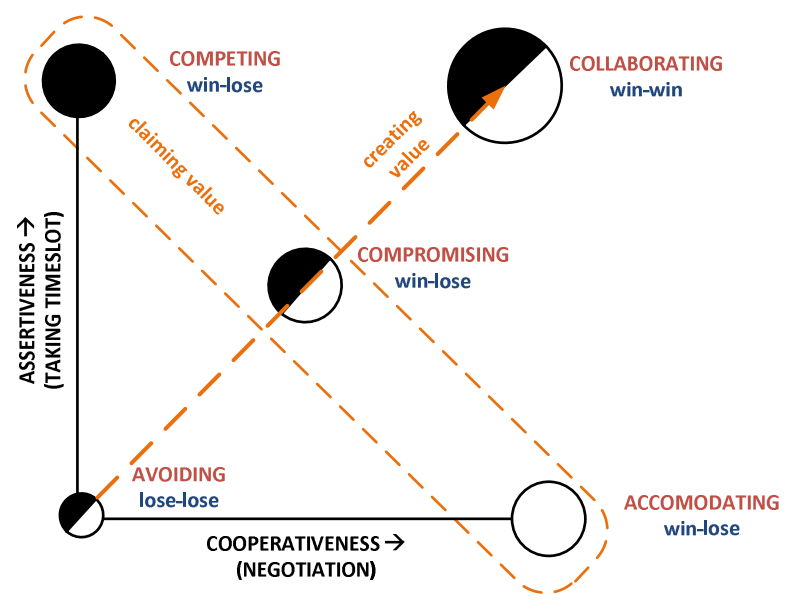

Fig. 2. Conflict Handling Modes

Conflict handling modes consist of two strategies, namely creating value and claiming value[10]. Creating value is a strategy to increase the size of the pie or to create more joint satisfaction. Creating value strategy includes avoiding mode, compromising mode, and collaborating mode. Claiming value is a strategy to take more of a limited pie. This strategy includes accommodating mode, compromising mode, and competing mode. Nevertheless, the best mode depends on the situation. Therefore, the negotiation must consider the advantages (to realize benefits) and costs (to minimize costs) of each mode for taking a proper action.

\section{Mechanism design}

In multiagent negotiation, agents interact to gain an agreement time for having a meeting. Negotiation is an approach for conflict handling by relaxing the constraint or revising personnel preferences in order to search a mutual time. Nevertheless, the emerging of new meeting request in heterogeneous community has potential to induce new conflicts. Since the process of negotation during iterations consumes many times, this process must be limited, such a way by defining its minimum preferences change (MC) principle and order-based change (OC) principle [5].

The study of multiagent negotiation also concerns about the personnel satisfaction. Personnel satisfaction is determined by personnel preferences fulfillment and denoted by personnel utility. Due to its form as group, meeting scheduling goal must be a joint satisfaction or global social welfare from all personnel invited. CTM which is discussed in mechanism design theory [5] is an approach in decision-making with social welfare consideration. This mechanism motivates personnels to reveal their true preferences without manipulation. This mechanism sets meeting scheduling problem and produces stable schedule with minimum risk of changing personnel preferences. This stability is also explained by Price of Anarchy (PoA), particularly in the discussion of Meeting Scheduling Game (MSG) [11].

\section{III.Host-to-Host Meeting Scheduling Negotiation Design}

There are two strategies used in this paper to overcome meeting scheduling conflict, namely taking timeslot, which is adapted from claiming value strategy, and leaving timeslot through negotiation, which is adapted from creating value strategy. The analogy given for claiming value is 'how to get a bigger pie', while one for creating value is 'how to make a bigger pie'. In meeting 
scheduling, a meeting with higher priority can use claiming value strategy or taking the timeslot. Otherwise, the meeting with lower priority must be negotiable by creating its value or by relaxing the constraints and preferences.

In negotiating personnel preferences, this paper uses personnel's availability time as basic information. This paper assumes that the main reason of personnel's reluctance to accept the meeting request is just because of personnel availability. The timeslot chosen must be free of conflict in two types of conditions. Firstly, the timeslot chosen has not been scheduled by another meeting (other personnel as host). For example, fig.2 shows the situation of meeting scheduling conflict. Host_2 that conducts a new meeting request wants to invite personnel_2, which has been scheduled by host_1. Host 1 can be one of the personnel invited (personel_1, personnel_2, personnel_5) or someone else as meeting coordinator. The meeting scheduling system will give notification that a conflict exists and needs to be negotiated. Secondly, the timeslot has not been scheduled as personal schedule (personnel as host). Since host_3 has only one member of meeting, host_3 conducts a personal schedule of personnel_5. Host_3 needs to negotiate with host_1 because the system will detect the conflict between host_1 and host_3 that both invite personnel_5. The dash arrow in fig. 3 below represents the communication between host-to-host in negotiation process.



Fig. 3. The communcation of Host to Host Meeting Scheduling Negotiation (H2MSN)

\section{A. Availability time}

This paper concerns about personnel availability time to be examined before scheduling a meeting. The host will use a meeting scheduler to get personnel availability time information then select some possible time from a global calendar[12]. The global calendar is an aggregation of personal calendars which are registered in the meeting scheduling system. It does not only consist of personnel availability time information but also historical information, such as accepted, rejected, and rescheduled meeting information while a negotiation occurs[13].

The existing meeting scheduling system gains personnel availability time information by collecting personnel's preference, meeting history, or calendar preference that is given by each personnel invited[13]. This global calendar scheme depends on personnel participation to fulfill their personal calendars as ilustrated in fig.4. This scheme has a risk of incomplete information because of the personnel's reluctance to provide their information due to some main issues in GCS, such as privacy and discretion issues[2]. Furthermore, the information provided that tends to be cryptic and the meeting priority that contains uncertainty weight makes the meeting scheduling problem become a "never ending" task or always get re-scheduled. 
Invited

Personnel

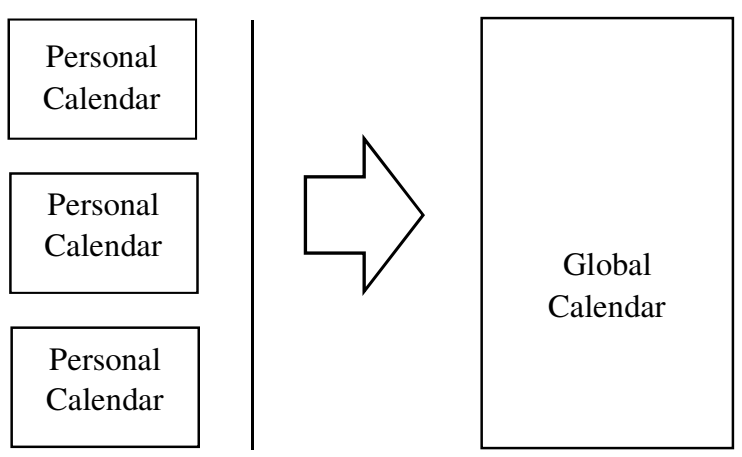

Fig. 4. Existing information flow of personnel availability time

In order to reduce the dependency upon personal calendar, this paper proposes a reversal scheme of personnel availability time information flow by using global calendar with interorganizational or host-to-host scope, such as shown in fig.5. This study utilizes the information of meeting that has been stored in the global calendar by each host. So, when scheduling a new meeting request, assigned meeting schedule in the global calendar can be retained and analyzed to guarantee personnel availability time. This scheme aims to achieve desired scheduled when conflict occurs by negotiation process instead of rescheduling process. The global calendar is not only used for one meeting or many meetings in parallel, but can be used for many meetings simultaneously. Thus, personal calendar is a part of global calendar that has been filtered by each personnel.



Fig. 5. Host to host information flow of personnel availability time

\section{B. Preference}

After getting convinced that the personnel invited to a new meeting request have no conflict with other meetings, this study attempts to create personnel preference satisfaction based on it. Logically, when personal schedule (personnel as host) is given a chance to be considered as personnel availability time, personnel preference is about the weight of meeting priority. Further work will disscuss the weight of meeting priority, which is represented by some values.

In this paper, the values are just given and assumed as a number between zero and nine. The value of zero means that a member of the personnel does not prefer the timeslot to be a meeting time since he/ she has another meeting schedule at the same time with a higher priority or cannot be canceled. Conversely, the value of nine means that the personnel member has a free time to be scheduled at that timeslot. These values will be calculated to determine the social welfare of each timeslot.

Social welfare in this paper is adapted from incentive compatibility and individual rationality that is included in CTM. Incentive compatibility (IC) is about personnel's preference to attend the meeting, while individual rationality (IR) is about personnel's possibility to join or not 
join the meeting[9]. To achieve optimal social welfare in meeting scheduling, CTM inserts variable tax (tax) to determine the payoff of each personnel member. A brief algorithmic description of CTM is given in Table 1 .

Table 1. An algorithmic description of the Clarke Tax Mechanism (CTM)

1. Calculate the value of social welfare for each timeslot by summing the utility value (preference) of the entire personnel for each timeslot.

2. Select a timeslot that has the highest value of social welfare.

3. Without involving utility of personnel- $i$, sum the value of social welfare for each timeslot (summing the value of utility besides personnel- $i$ for each timeslot)

4. If the value of the highest social welfare in point(c) refers to the same timeslot in point (b), the tax for personnel- $i$ is zero or not taxed. Conversely, if without counting the utility of personnel $-i$ results in another timeslot as higher social welfare, then the personnel- $i$ will receive a tax amount from the difference value of social welfare.

5. Personnel payoff value is the value of utility in the selected timeslot reduced by its tax.

Table 2 below gives the example of utility value that represents personnel's preferences. Since personnel 4 gets a tax, this personnel member is not recommended to be replaced in a negotiation process, or the social welfare must be recalculated. The availability time of personnel 4 is determined mostly in the selected timeslot.

Table 2. Personnel's Payoff

\begin{tabular}{|c|c|c|c|c|c|c|c|c|c|c|c|c|}
\hline \multirow{2}{*}{ Personnel } & \multicolumn{5}{|c|}{ Timeslot } & \multicolumn{5}{|c|}{ Timeslot } & \multirow{2}{*}{ Tax } & \multirow{2}{*}{ Payoft } \\
\hline & 1 & 2 & 3 & 4 & 5 & 1 & 2 & 3 & 4 & 5 & & \\
\hline Personnel 1 & 0 & 6 & 6 & 4 & 0 & $* 34$ & 18 & 21 & 23 & 29 & 0 & 0 \\
\hline Personnel 2 & 9 & 4 & 3 & 9 & 9 & $* 25$ & 20 & 24 & 18 & 20 & 0 & 9 \\
\hline Personnel 3 & 8 & 2 & 8 & 4 & 8 & $* 26$ & 22 & 19 & 23 & 21 & 0 & 8 \\
\hline Personnel 4 & 9 & 7 & 1 & 3 & 4 & 25 & 17 & $* 26$ & 24 & 25 & 1 & 8 \\
\hline Personnel 5 & 8 & 5 & 9 & 7 & 8 & $* 26$ & 19 & 18 & 20 & 21 & 0 & 8 \\
\hline Utility & $* 34$ & 24 & 27 & 27 & 29 & & & & & & & \\
\hline
\end{tabular}

\section{Negotiaton strategy}

This study adapts conflict handling mode in fig. 2 to meeting scheduling nature by using some adjustments. Firstly, assertiveness is similar to the action taken, namely leaving timeslot or taking timeslot. Secondly, cooperativeness is similar to the negotiation environment, which is intragroup or inter-group negotiation as shown in fig. 6.

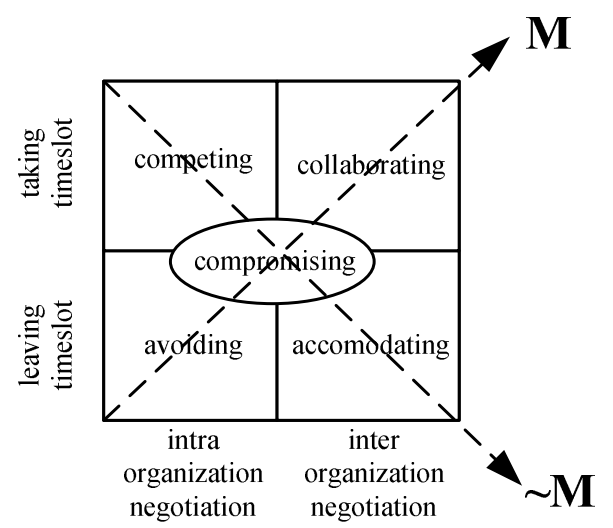

Fig. 6. Conflict Handling Modes in Meeting Scheduling 
Since a new meeting request $(\mathrm{M})$ comes and encounters the conflict with scheduled meeting $(\sim \mathrm{M})$, the negotiation strategy is about creating the value. The strategy is relaxing the constraint, revising the threshold, or adding personnel. On the other hand, scheduled meeting needs to claim the value by replacing the personnel or revising the threshold. Therefore, a new meeting request has avoiding, compromising, and collaborating modes as conflict handling mode while scheduled meeting has competing, compromising, and accomodating modes.

\section{Conclusion and Future Works}

This paper has proposed host-to-host meeting scheduling negotiation as an approach to solve time conflict. There are two points discussed here, the benefit of using host as agent to gain personnel information and to negotiate the other agent to raise a stable schedule by conflict notification. Personnel information is about their availability and preferences that come from personnel's role in other meetings. This study also elaborates the negotiation strategies by adapting conflict handling modes. Host-to-host meeting scheduling negotiation is aimed to produce a meeting schedule that is stable in the dynamic calendar density of personnel. Furthermore, this approach keeps the schedule quality by considering the social welfare of personnel's group.

Negotiation strategy with several scenario will be discussed in the future works. The use of calendar density and CTM needs to be elaborated to make the negotiation process more complete. Therefore, the efectiveness of host-to-host meeting scheduling negotiation will be continued by its simulation.

\section{References}

[1] J. Grudin, "Groupware and social dynamics: eight challenges for developers," Communications of the ACM, vol. 37, no. 1, pp. 92-105, 1994.

[2] H. Lee, "Your time and my time: a temporal approach to groupware calendar systems," Information \& Management, vol. 40, no. 3, pp. 159-164, 2003.

[3] L. Palen, "Social, individual and technological issues for groupware calendar systems," in Proceedings of the SIGCHI conference on Human factors in computing systems: the CHI is the limit, 1999, pp. 1724.

[4] Jacques Wainer, Paulo Roberto Ferreira, and Everton Rufino Constantino, "Scheduling meetings through multi-agent negotiations," Decision Support Systems, vol. 44, no. 1, pp. 285-297, 2007.

[5] Toramatsu Shintani, Takayuki Ito, and Katia Sycara, "Multiple negotiations among agents for a distributed meeting scheduler," in MultiAgent Systems, 2000. Proceedings. Fourth International Conference on, 2000, pp. 435-436.

[6] Behrouz Far, Tom Wanyama, and Sidi O Soueina, "A Negotiation Model for Large Scale Multi-Agent Systems," in Information Reuse and Integration, 2006 IEEE International Conference on, 2006, pp. 589-594.

[7] F Wang, "Adaptive meeting scheduling for large-scale distributed groupware," BT technology journal, vol. 21, no. 4, pp. 138-145, 2003.

[8] Gilad Zlotkin, Jeffrey S. Rosenschein Eithan Ephrati, "A Non-manipulable Meeting Scheduling System," AAAI Technical Report WS-94-02, 1994.

[9] Elisabeth Crawford and Manuela Veloso, "Mechanism design for multi-agent meeting scheduling," Web Intelligence and Agent Systems, vol. 4, no. 2, pp. 209-220, 2006.

[10] Keeneth W.Thomas, Introduction to Conflict Management.: CPP,inc., 2002.

[11] Alon Grubshtein and Amnon Meisels, "Cost of cooperation for scheduling meetings," in Intelligent Distributed Computing III.: Springer, 2009, pp. 227-236.

[12] Abid Saeed Khattak, Malik Sikander Hayat Khiyal, and Sanam Shahla Rizvi, "Verification \& Validation of a Multi Agent Meeting Scheduling Simulation Model," Journal of Computer Science, vol. 2, no. 1, pp. 47-64, 2014.

[13] Elhadi M Shakshuki and SM Mozammal Hossain, "A personal meeting scheduling agent," Personal and Ubiquitous Computing, pp. 1-14. 